\title{
OS PARADOXOS DA IMAGEM
}

Monique Sicard $^{* *}$

\begin{abstract}
Resumo
Originalmente, a imagem é o reflexo da realidade em uma superfície refletora. Mas ela é, também, simultaneamente, o que parece (mimesis), o que se vê (phanein), o conhecimento que dá acesso à realidade (eidos) e o que forma a visão/ilusão (phantasma) que leva a crer na existência de uma realidade. A ciência fala pouco das imagens que utiliza, tornando-as transparentes, quase imateriais. A análise das imagens de ciência leva a compreender tanto o seu funcionamento no seio do campo científico quanto a natureza da imagem em geral. Ela é ao mesmo tempo o que impede o acesso ao real e ao conhecimento e o que permite esse acesso.
\end{abstract}

A ciência, a medicina, criam imagens em grande número. Destinadas oficialmente a produzir conhecimentos, portando o novo, essas imagens são a base de estéticas originais. Quando as recebemos, elas deslocam nossas posições diante dos objetos do mundo, dos outros, de nós mesmos.

Em que tais imagens esclarecem o funcionamento da ciência, da construção do conhecimento? Quais traços elas deixam em nossas culturas visuais? Como, em contrapartida, estas se encontram marcadas por aquelas?

Ingênuo aquele que acredita escapar ao empreendimento das imagens poderosas criadas pelos inventores, descobridores, especialistas, cientistas, médicos, cirurgiões ou

\footnotetext{
"Traduzido de "Les Paradoxes de l'Image", publicado em Sciences et Médias, 21, CNRS Éditions.
}

" Laboratoire Communication et Politique, Paris, CNRS.

Rua, Campinas, 6: 25-36, 2000 
pesquisadores. Os trabalhos de Copérnico, de Galileu, de Kepler, mas também os de Darwin ou de Pasteur, os de Wegener e, mais próximos de nós, os satélites de observação, as sondas espaciais, as câmaras de elétrons positivos são geradores de imagens que remexem os olhares que temos sobre o mundo que nos cerca e sobre nós mesmos. Neles se ancoram os sucessos da ciência; deles nasce seu poder. As racionalidades científicas têm uma grande parte de responsabilidade na construção do magazine de imagens em meio ao qual vivemos.

Não são as equações, os cálculos, que se encontram no ponto de partida de um trabalho científico, mas as imagens (Lévy-Leblond, 1996). Motores essenciais de todo trabalho de pesquisa, elas se desenvolvem, precisam-se, instalam-se, em relação profunda com a utilização de instrumentos de ver e de registrar. Certamente, as imagens em questão aqui são também imagens interiores, imagens do espírito. Imagens bem materiais entretanto (desenhos, fotografias, imagens de todo tipo, cinematografias, imagens numéricas) nascem em estreita ligação com as precedentes, e por sua vez as modificam. O que elas fazem nos ensina ao mesmo tempo sobre suas verdadeiras funções no seio do campo científico e sobre a natureza da imagem em geral.

\section{Definições}

Deixar de lado em um primeiro momento as imagens psíquicas e aceitar uma definição trivial de imagem apresenta uma dupla vantagem. A de evitar restringir a definição de um conceito muito móvel, muito rico para ser imobilizado. A de ancorar os debates em objetos visíveis.

Dispomos de apenas uma palavra em francês, quando existem duas palavras em inglês: image (o reflexo no espelho, a imagem real, virtual, a imagem mental) e picture (a ilustração, a imagem material, a fotografia, o quadro). A imagem, na origem, é o reflexo da realidade sobre uma superfície refletora. Ela é também, ao mesmo tempo, o que parece (mimesis), o que se vê (phanein), o conhecimento que dá acesso à realidade (eidos), mas também o que forma a visão, a ilusão (phantasma) que leva a crer na existência de uma realidade.

Assim, a imagem é ao mesmo tempo o que impede o acesso ao real e ao conhecimento e o que permite esse acesso (Besnier, 1995); a imperfeição de um reflexo e a realidade 
mesma. Ela é sobretudo um objeto do qual não se acaba de delimitar os usos, as funções, os funcionamentos, os impactos, os poderes; características nas quais dever-se-ia fundamentar uma definição fina e precisa da imagem.

As imagens materiais são, aqui, simplesmente definidas como "figurações bidimensionais que provocam uma parada, uma memorização, abrindo caminho para uma leitura". Observaremos que nem todas as imagens materiais são bidimensionais: existem imagens 3D, imagens animadas, etc. Mas a imagem é geralmente recebida como uma superfície. As imagens dos sonhos não são exceção: é-nos geralmente difícil descrever o que há atrás do seu plano/superfície.

Conseqüentemente, toda imagem é recebida: uma figuração bidimensional que não é recebida não é uma imagem. Ela permanece na ordem de uma simples visão: conjunto de traços, de cores ou de manchas, perceptíveis certamente, mas que não criam memória; mesmo se a imagem é utilizada para fins cognitivos, mesmo se ela é empecilho em um raciocínio, a sua recepção é uma recepção sensível. Ela possui sempre uma estética, entendida aqui no sentido primeiro de recepção sensível; uma figuração bidimensional pode tornar-se imagem pelo exercício da vontade. O que é imagem para um pode não ser imagem para outro. Portanto, a estética da recepção define a imagem.

Importa notar que a definição de imagem proposta aqui é ampla e não se limita a uma imitação, uma semelhança. As imagens de ciência possuem relações privilegiadas com os seus objetos. Entre eles pode existir uma semelhança de natureza, de funcionamento, de essência. Mas a eficácia da imagem situa-se também em uma diferença: o que é buscado não é a identidade entre o mapa e o território, mas a sua disparidade. A semelhança das aparências não é procurada de maneira privilegiada.

Seria ilusório enfim reduzir a imagem a completas figurações, abstratas ou realistas, coloridas ou sem cor (Dagognet, 1973). Os grafos, gráficos, esquemas, quadros, diagramas, equações, são imagens, desde que dão lugar a figurações mentais. Seria ilusório pensar que todas as imagens de ciência são imagens imediatas de um referente real. As imagens obtidas nas câmaras de ar ou nos grandes aceleradores de partículas são imagens de traços, às vezes imagens de traços de traços.

Enfim, nem toda imagem de ciência é traço de um objeto. Ela é também visualização de equações ou de conceitos da matemática ou da física, ou mesmo a formalização eficaz e colorida de dados muito abundantes para serem facilmente tratados. Essas imagens

Rua, Campinas, 6: 25-36, 2000 
de ciência espalham suas tintas entre dois paradigmas icônicos. O primeiro, do qual a fotografia aérea poderia constituir um tipo, capta o acaso, não rejeita o incompreendido. O segundo, representado pelo esquema de funcionamento, aponta o que deve ser visto, torna visíveis certezas de resultados adquiridos. As imagens de pesquisa pertenceriam antes à primeira categoria, quando à divulgação científica convém melhor a segunda.

Entretanto, não dissociar estas duas categorias de imagens permite melhor compreender a economia global das imagens de ciência. A explicação, com efeito, não é reservada às imagens da divulgação; e a produção de conhecimentos novos não é a única fonte das imagens da pesquisa. Há explicação nas imagens de pesquisa; o ato de divulgar leva também à construção de conhecimentos novos. Mesmo que os lugares de sua publicação sejam diferentes, e que as funções não sejam idênticas, ambas as categorias interferem. Elas se interrogam mutuamente.

As imagens de ciência são freqüentemente imagens técnicas, frutos de "olhares intrumentalizados" (Latour, 1991), mas esta propriedade não é a única: o grafite não está prestes a desaparecer dos canteiros de exploração e dos laboratórios. Entretanto, enquanto os elementos da realidade não são apreensíveis a não ser pelas próprias imagens, estas desempenham um papel crucial no diálogo entre o homem e a máquina. Seja a câmara de elétrons positivos, o microscópio eletrônico, o aparelho de radiografia ou o captador de satélite, a máquina desempenha o papel de tradutor: o "grande livro da natureza" se escreve em imagens.

O ser humano quer ver ou quer saber; a máquina "vê" o invisível e o transforma em imagem visível. Assim, a capacidade de um objeto de emitir, refletir ou absorver os sons, os ultrasons, os elétrons, as radiações eletromagnéticas não visíveis, etc., se traduz na forma de imagem. $\mathrm{O}$ aparato de imagens científicas que integra nos mesmos instrumentos a recepção das propriedades do real, sua tradução em imagens e a análise dessas mesmas imagens, não é mais uma simples analogia, mas já um funcionamento, uma compreensão. À maneira dos desenhos de Leonardo da Vinci, carrega em si os germes de uma explicação.

É utópico pensar essas imagens como se elas fossem sem subjetividade. Mesmo o satélite que nos sobrevoa, mesmo a câmera no ascensor, possuem autores cheios de intenções. Todas as imagens de ciência, quaisquer que sejam, são assim fortemente marcadas por escolhas culturais, históricas, individuais. 


\section{Pensar as imagens}

As imagens podem assim ser pensadas como um dos elementos de um quadrilátero dinâmico, formado pelo real, o olho, a máquina e a própria imagem, em que todos os instrumentos funcionam simultaneamente respondendo uns aos outros, segundo a sua especificidade.

Algumas hipóteses iniciais guiam esses propósitos:

1) a análise por fragmentos dissolve a imagem quando não leva em conta as ligações entre o local e o geral, o punctual e o conjunto. A imagem é uma recepção global, imediata; ela é portanto indivisível;

2) mesmo as imagens mais fixas são de dinâmicas instáveis. Um estilhaço de luz, uma outra imagem, um quadro, um quarto de segundo, um barulho que cessa, uma modificação do lugar da projeção ou da exibição, ou simplesmente o tempo que passa, fazem oscilar os seus sentidos de forma vertiginosa. Essa labilidade da imagem é essencial;

3) uma imagem não produz assim nenhum enunciado por si mesma. Ela não é em si portadora de verdade alguma, mas adquire essa verdade tanto no funcionamento desses fatores de ativação quanto no de uma leitura;

4) uma mesma imagem pode ser recebida de maneira contraditória por diferentes sujeitos. A fotografia de um rosto deformado pela sífilis gera tanto a compaixão quanto a rejeição violenta. Ela pode também suscitar interrogações: o que é isto? que relações o fotógrafo estabelece com a doença? para que foi utilizada esta imagem?

5) essa labilidade, essa capacidade de guardar as contradições, essa riqueza mesma, fazem de uma imagem a candidata a múltiplas legitimações.

6) cada imagem comporta ainda uma parte não dominada, não intencional. Esse acaso se prende tanto à sua leitura quanto à sua produção. No campo científico, o "acaso de produção" é esperado: ele é portador de novidade; as imagens cuja fabricação é automatizada não são exceção.

Um dos méritos das imagens de ciência é de nos convidar a pensar na externalidade das imagens, sua remissão ao mundo (Dagognet). Ora, essa externalidade raramente tem sido pensada pelos filósofos. As referências aos trabalhos de Charles S. Peirce (18391914) são clássicas desde então (Esquenazi, Fleury-Vilatte, Pequignot, 1996). Lembremos que para Peirce o signo é "alguma coisa que remete a outra coisa para alguém". Um 
signo (ou representamen) possui três componentes; ele cria no pensamento daquele que o interpreta um novo signo (ou interpretante), ele toma o lugar de seu objeto, ele ocupa esse lugar em função de uma espécie de idéia chamada por Peirce de fundamento do signo: "Now a sign has, as such, three references: first, it is a sign to some thought which interprets it; second, it is a sign for some object to which in that thought it is equivalent; third, it is a sign, in some respect or quality, which brings it into connection with its object"" (Peirce, 5-283).

Um signo é em parte determinado pelas característ cas de seu objeto. Para Peirce, as ligações que ele entretém, para alguém, com seu objeto, são de três ordens: o índice, o ícone e o símbolo. $\mathrm{O}$ índice, em continuidade direta com o referente, possui com ele algo em comum. $\mathrm{O}$ ícone não é diretamente afetado pelo objeto que o designa, mas entretém com ele uma ligação analógica. O símbolo é ligado ao que ele designa por uma convenção. Esta classificação foi mantida, às vezes retomada nos trabalhos contemporâneos sobre fotografia. Esta última, ao mesmo tempo impressa em uma superfície sensível de irradiações eletromagnéticas emitidas ou refletidas pelo objeto que ela representa, e "impressão de realidade", é freqüentemente caracterizada como ícone indicial.

O interesse atual suscitado pela parte do indicial nas imagens (Barboza, 1996) manifesta a insistente questão do testemunho e da prova. De que a imagem é prova? É é ela prova de alguma coisa? Se a imagem é considerada como signo segundo a definição de Peirce, e se apenas os fatos são uma prova, então apenas a imagem indicial seria prova de alguma coisa. Somente ela garantiria as possibilidades de um acesso exato a seus objetos. Assim, o advento da fotografia na metade do século XIX constitui uma dupla revolução, científica e icônica. A imagem fotográfica diretamente afetada por seus objetos desempenha um papel privilegiado em matéria de construção da prova; portanto, ela pode ser considerada como uma nova realidade. Paradoxalmẹte, essas imagens indiciais que favorecem a construção da prova científica geram uma emoção específica: é-se sensível ao traço deixado por uma coisa, pois ele é a própria coisa. Estas aporias raramente são explicitadas.

\footnotetext{
"NT: "Um signo tem, como tal, três referências: primeiro, é um signo para o pensamento de alguém que o interpreta; segundo, é um signo em relação a algum objeto ao qual é equivalente naquele pensamento; terceiro, é um signo, em algum aspecto ou qualidade, que traz conexão com seu objeto".
}

Rua, Campinas, 6: 25-36 , 2000 
Por outro lado, a classificação em índice, ícone e símbolo permanece insuficiente para dar conta da diversidade de imagens produzidas pela ciência. Onde classificar, por exemplo, em tais esquemas, as inúmeras imagens que dão conta de propriedades invisíveis, mas que não apresentam nenhuma analogia de forma com seu objeto, nenhuma ligação direta, e não foram diretamente afetadas por sua presença em sua fabricação? Onde situá-las quando os códigos de formas, de traços, de cores, não remetem a nenhuma convenção preestabelecida? Como dar conta do concurso de índices, ícones e símbolos de modificações trazidas pela imagem na consideração do real: a imagem favorece a compreensão de mecanismos passados, permite antecipar uma evolução, dá conta do mundo observável, mensurável e quantificável, incita à ação, induz uma percepção diferente ou de melhor qualidade? Como ela age, o que ela faz?

Onde situar as imagens concebidas como modelos simplificadores da realidade, mas que a esclarecem, como se esclarecem eles mesmos, simultaneamente, no curso de sua concepção e de sua produção? Onde situar as imagens ditas numéricas, que integram em si mesmas seus próprios instrumentos de quantificação e de análise?

A diversidade de imagens de ciência, sua riqueza, manifestam a pobreza do pensamento e da análise das relações que ligam a imagem a seus objetos. A fotografia do século XIX remete não somente ao homem que marcha, não somente à marcha do homem, mas também à sua própria eficácia como "modelo". Tais imagens por ressonância magnética nuclear mostram os primeiros potenciais de uma possível esclerose diante do aparecimento do menor sintoma. Longe da nostalgia de um passado desaparecido, a qualidade testemunhal da imagem é a afirmação de um valor previsível. A imagem antecipa a compreensão de um funcionamento, de uma evolução.

\section{Construir o verdadeiro com o duvidoso}

A ciência produz, utiliza imagens a despeito de inúmeras contradições: ela enaltece o rigor dos discursos, mas suas imagens são globais, não discursivas, não refutáveis, dotadas de uma irredutível polissemia; ela utiliza as imagens como instrumentos de acesso ao conhecimento quando estas últimas exigem, para funcionar, uma adesão prévia; ela fala pouco das imagens, tornando-as transparentes, quase imateriais. Como se a imagem de um coração fosse só um ventrículo, como se a imagem de um raio de lua fosse só um 
satélite; enfim, os inventores, descobridores, especialistas, têm, em face das imagens, comportamentos contraditórios. A gama de discursos sobre a imagem varia do fascínio à iconofobia. Suzanne de Cheveigné fez aparecerem essas contradições em entrevistas específicas realizadas com pesquisadores que utilizam microscópios em campos próximos. A imagem é perigosa: ela é sedutora. É preciso evitar enganar-se com suas qualidades estéticas. E, no entanto, essa beleza mesma, entusiasmante, é criadora de ligações entre os cientistas e os não-cientistas.

Assim, as imagens de ciência têm claramente poucas coisas a ver com a recepção mimética de um mundo real por uma janela aberta, como se fossem fotografias. E, no entanto, elas são utilizadas como se fossem esta natureza que fala por si mesma. Os cientistas apresentam freqüentemente suas imagens como se tais ligações fossem evidentes. A imagem de uma galáxia é uma galáxia, a imagem de um pâncreas é um pâncreas. A imagem testemunha. Tudo se passa como se a própria imagem material não existisse. Certamente, os cientistas não caem nessa confusão, mas as imagens são freqüentemente apresentadas como suporte de um discurso, prova para o visível: "Vocês vêem bem!" As intenções, as escolhas que introduziram a realização, os modos de fabricação, as restrições e artefatos, são deixados em silêncio. Como se a negação da materialidade da imagem constituísse uma garantia de objetividade. Como se ela garantisse, ao invés de realidades virtuais, uma imersão total no mundo, e portanto uma maior eficácia.

Assim funciona a prova pela imagem. Em seus inícios, a fotografia foi portanto valorizada pelos cientistas como materialização de uma natureza "que falaria por si mesma", como se ela fosse o "texto do mundo" (Jeanneret, 1994). Assim, foram pesquisados modos de autentificação da imagem pelo escrito; porque o escrito é, mais do que a imagem, uma garantia de seriedade, de verdade. Em uma das primeiras fotografias submarinas realizadas na virada dos séculos XIX e XX por Louis Boutan, o escafandro tem uma placa na qual está escrito: "Fotografia submarina". Uma das primeiras radiografias realizadas no fim do século XIX é acompanhada do texto seguinte: "Fotografia de uma caixa de madeira fechada, amarrada e lacrada, contendo uma amostra de ouro e sua corrente bem embaladas". Legitimando as novas imagens da radiografia e os jogos de tomadas que os acompanham, o texto desculpabiliza o autor cientista.

Assim, constroem-se conhecimentos científicos a partir de imagens que não são em si mesmas provas de nada senão de sua própria existência: essas imagens funcionam apenas 
inseridas nos sistemas de racionalidade que misturam escritos, saberes implícitos, não ditos, outras imagens materiais e psíquicas. Elas levaram assim a fundar disciplinas, a construir campos inteiros de conhecimentos científicos: seria bem difícil imaginar o que seria atualmente a astronomia, a biologia, a arqueologia, a medicina, sem imagens.

Nenhum astrofísico, nenhum astrônomo está de acordo com um valor de racionalidade científica para falsas perspectivas de imagens compostas, para falsas cores de imagens de planetas. Nenhum físico está de acordo com um valor analógico para elevações da superfície de um objeto observado no microscópio com efeito-túnel e que se pressupõe mostrar os átomos. No entanto, todos fazem como se, como se os planetas fossem bem coloridos, como se as elevações figuradas em superfície fossem os átomos. Essas denegações da realidade não são sem conseqüência. Por força de funcionalidade, acabase por acreditar. Essa falsa indicialidade é utilizada fazendo crer: essa pseudo-ausência de autor funciona como garantia de objetividade. "Esta é a imagem do Big Bang!", afirmam. Como se o fundo barulhento captado pela sonda Cobe e traduzida em azul e rosa tivesse alguma coisa a ver com o aspecto do Big Bang mesmo. Da mesma maneira se escreve: "Esta é a imagem de um meteorito captado por um telescópio amador!" Entenda-se por isso: esta imagem, porque é ingênua, é certeza e prova!"

\section{Jogos}

Por que razões a imagem, e com ela seu suporte material, suas fabricações, são assim ocultadas até a instalação de uma utopia imaterial? O que aconteceria se elas fossem julgadas, analisadas, expostas em praça pública, se a parte dos autores fosse mostrada e com ela a subjetividade disso que se apresenta como automático e objetivo?

As pesquisas específicas realizadas sobre as imagens do buraco negro (Sicard e Marck, 1995), imagens calculadas a partir de leis da relatividade geral e portanto, a priori, de uma exatidão insuspeitável; aquelas realizadas sobre as imagens do microscópio eletrônico (Mercier, 1987) mostraram, assim, a partir de análises críticas internas ou semi-internas, a parcela de escolha individual e cultural na criação de imagens apresentadas como expressão direta de uma realidade ou de um cálculo. Assim, a perspectiva utilizada para construir as imagens ou simplesmente para lê-las é, de modo freqüientemente não consciente, uma perspectiva diretamente herdada do Renascimento. Esquece-se então 
de boa vontade que tal perspectiva central não facilita a análise científica quantificada das imagens, porque ela não respeita as relações de distância ou de superfície.

A supervalorização heurística da imagem bem poderia não ser mais do que uma fachada que esconde uma tensão entre uma economia oficial de imagens e sua economia privada (Mondzain, 1996). De um lado, a exibição de uma modernidade, a alegação de máquinas e dispositivos; do outro, o desejo de imagens.

À diferença do papel afixado de participação na construção de saberes científicos, as imagens de ciência possuiriam assim múltiplas funções. Os mecanismos, as óticas, as engrenagens, são então legitimadores. Eles protegem a imagem, escondem-na ao exibi-la de uma maneira talvez que provoca a sua própria visibilidade. Eles desempenham um papel não negligenciável no desenvolvimento das utopias, na instalação de adesões. Eles liberam o pensamento, protegendo o imaginário. O fato de que as imagens sejam instrumentalizadas não significa que elas sejam os registros que a mão do homem não produziu. Elas são portanto materializações de subjetividades.

Essas estratégias de instalação da prova, de estabelecimento de uma crença, são apenas provisórias e, em certo sentido, irrisórias. A capacidade das imagens de mudar de sentido sob o efeito de uma ativação faz delas instrumentos privilegiados da armadilha: acontece freqüentemente que uma imagem seja brandida como prova, quando se sabe que ela não basta para garantir certezas. A labilidade da imagem, em contrapartida, torna efêmera a instalação dessa armadilha. Uma imagem utilizada como prova em um dado momento pode não ser mais em outros. De certo modo, as imagens são reveladas por sistemas de legitimação que preexistem ao seu advento e à sua aceitação. Se tais sistemas de legitimação funcionam de maneira insuficiente, as imagens não são aceitas. Ora, os diagramas de defração que mostram a existência de simetrias cristalinas de ordem cinco foram por muito tempo conservados no fundo das gavetas, antes de ser interpretados. No fim do século XIX, os traços deixados sobre uma placa sensível cinco anos antes da descoberta dos raios X por W. C. Röntgen não foram levados a sério. Para serem aceitas, as imagens devem surgir em terrenos teoricamente, emocionalmente, institucionalmente preparados. Elas devem ser esperadas. Elas são então, de alguma maneira, recebidas antes de serem vistas. Se a ciência, naturalmente desconfiada diante dos duplos, das ilusões e dos fascínios, aceitou bem a fotografia na metade do século XIX, é porque tais procedimentos de legitimação foram realizados com diligência. 
Qual é então a natureza dessas imagens de ciência? Que funções elas desempenham de fato? Inexatas e oferecendo apenas um acesso incerto ao real, que papéis elas podem desempenhar além de seus usos heurísticos? A evidenciação de paradoxos ligando a ciência e as imagens leva a novas hipóteses. E se a ciência não fosse impregnada dessa vontade indefectível de ter acesso à realidade? E se a ficção lhe interessasse mais do que a brutalidade dos fatos? E se as imagens fossem não um mergulho em um mundo de ilusões, mas o acesso enfim oferecido a uma construção dosada de realidade e de ficção?

Limitar-se entretanto somente à hipótese de uma denegação dos fatos para explicar o uso das imagens seria esquecer que um prazer estranho da confrontação com o real existe sim, notadamente no mundo científico. Este real dos cientistas evolui freqüentemente em um isolamento maravilhoso, um terreno paradoxal, propício à fermentação de poderosos imaginários, eles próprios produtores de imagens materiais. O excesso de real tem o poder de tornar as coisas estranhas, como surreais. Jean Painlevé, Luis Buñuel, Jean-Luc Godard observaram bem esse ponto de convergência do cinema com a ciência, essa exigência absoluta de visibilidade, essa embriaguês que nos leva a outro lugar. As maquinarias de captação de imagens, sejam câmeras ou instrumentos de ecografia, facilitam essa redescoberta do visível. Elas convidam desde então a novos olhares.

As imagens aparecem então como portadoras, em si mesmas, de sistemas aparentemente contraditórios, ao mesmo tempo objetivos e subjetivos. Instrumentos de visualização, de registros, elas são também o recobrimento de um encantamento, que funciona ao mesmo tempo como fator de evasão e de adesão. Essa vontade de encantamento é particularmente nítida nas imagens da medicina, que passaram abruptamente de tristes realidades do Larousse médico à imagem maravilhosa da dor: desde então em primeira página do jornal Libération, o vírus da hepatite $\mathrm{C}$ parece uma bola de natal. Graças às imagens, o corpo doente tem direito de aparecer na grande mídia.

A função principal das imagens não seria dar visibilidade a um real invisível preexistente, do qual elas constituiriam as provas. As imagens não seriam representações, nem revelações, nem simplesmente instrumentos de visão, nem simples superfícies de registro. Suscitando adesões espontâneas das quais conviria buscar os fundamentos, elas são uma evasão. Mesmo se esse poder da imagem é utilizado para fazer crer. A ciência afirma que suas imagens materiais são a apresentação de um invisível real do qual elas constituem uma prova, quando elas são também a apresentação de um invisível 
mental, o recobrimento de uma liberdade perdida desde o advento da ciência moderna: a da relação sensível com as coisas.

Esses mundos construídos pelas imagens, recobertos de ciência e de fidelidade à natureza, nos aparecem, então, porque escondem talvez mais do que mostram, como a manifestação de olhares livres dissipados das restrições da representação. Testemunham a força estética dela, os pontos de vista radicalmente novos que elucidam. Se as imagens de ciência são um saber, esse saber ultrapassa largamente o conhecimento do objeto a que elas parecem referir.

\section{Résumé}

L'image, à l'origine, est le reflet de la réalité sur une surface réfléchissante. Elle est ainsi à la fois ce qui ressemble (mimesis), ce qui on voit (phanein), la connaissance offrant accès à la réalité (eidos), mais ainsi ce qui forme l'écran, l'illusion (phantasma) qui fait croire à l'existence d'une réalité. La science parle peu des images utilisées, les rendant transparentes, presque immatérielles. L'analyse des images de science conduit a comprendre à la fois leur fonctionnement au sein du champ scientifique et la nature de l'image en général. Elle est à la fois ce qui empeche l'accès au réel et à la connaissance et ce qui permet cet accès.

Tradução: M. Onice Payer

\section{BIBLIOGRAFIA}

Barboza, P. (1996) Du Photographique au Numérique. Paris, L'Harmattan.

Besnier, J.-M. (1995) "Introduction" in Virtualité et réalité dans les Sciences. Gif, Frontières.

Dagognet, F. (1973) Écriture et iconographie. Paris, Vrin. 